\title{
Mean term follow-up of a series of post-traumatic syringomyelia patients after syringo-peritoneal shunting
}

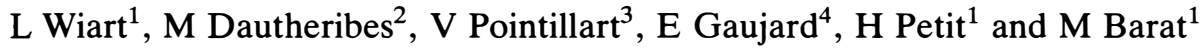 \\ ${ }^{1}$ Service de Rééducation Fonctionnelle Neurologique; ${ }^{2}$ Service de Neurochirurgie; ${ }^{3}$ Service d'Orthopédie, Groupe \\ Hospitalier Pellegrin, 33076 Bordeaux Cedex; ${ }^{4}$ Clinique de Rééducation Les Grands Chênes, 33021 Bordeaux \\ Cedex, France
}

\begin{abstract}
We report the follow-up of a series of post-traumatic syringomyelia patients treated by syringo-peritoneal shunting (SPS). The neurological status was determined following the international ASIA/IMSOP standards for neurological classification of spinal cord injury; this was completed by a modified Silberstein classification that identifies the ascending neurological symptoms as well as the increasing myelopathic symptoms in patients with post-traumatic syringomyelia. Magnetic resonance imaging (MRI) was systematically performed to assess the presence of a postoperative residual syrinx or of meningeal fibrosis. Eight patients were studied (five men, three women) with an age ranging from 17 to 54 years (mean of 30.7 years) at the time of the spinal cord injury. Three had a complete or nearly complete paraplegia, five were incomplete. The post-traumatic syringomyelia was diagnosed from 2 to 8 years after the spinal cord injury and was treated by syringoperitoneal shunting. Early complications occurred in three patients: (1) displacement of the catheter, (2) obstruction of the catheter, and (3) haematomyelia, which disappeared after a new surgical procedure was performed. The postoperative follow-up ranged from 3 to 9 years (mean of 4.5 years). The neurological level decreased in every case and the ascending neurological symptoms decreased or were stabilised in seven patients. The postoperative ASIA/IMSOP scores and the increasing myelopathic symptoms improved in four patients but worsened in the four others, incomplete. The MRI showed an important decrease of the syrinxes in every patient associated with a serious meningeal fibrosis in five cases. Syringo-peritoneal shunting seems to be efficient in the treatment of the syrinx but may have a poor effect regarding the prevention of meningeal fibrosis. The ascending neurological symptoms are more sensitive than the increasing myelopathic symptoms to syringoperitoneal shunting especially in those with incomplete paraplegia.
\end{abstract}

Keywords: spinal cord injury; post-traumatic syringomyelia; syringo-peritoneal shunting

\section{Introduction}

Post-traumatic syringomyelia (PTS) is an uncommon pathology considered to affect from 0.3 to $3.2 \%$ of patients with spinal cord injuries (SCI). ${ }^{1,2}$ The consequences may be very serious for patients who are already very disabled and handicapped. Nowadays, shunting the syrinx such as syringo-pleural shunting or syringo-peritoneal-shunting (SPS) is a possible treatment for PTS. ${ }^{2,3}$ There is still a lack of data in the literature regarding the neurological and magnetic resonance imaging (MRI) findings on follow-up after a period of some years. We present a retrospective study of the mean term results of SPS in a series of eight patients operated on by the same surgeon and followed up at the University Hospital of Bordeaux, France.

\section{Methods}

\section{Clinical and MRI evaluation}

The preoperative assessment was studied from the medical files. The postoperative evaluation was carried out during 1993 after a delay of at least 3 years following the injury. The neurological status was determined according to the ASIA/IMSOP impairment scale. ${ }^{4}$ This was completed by a classification modified by Silberstein. ${ }^{5}$ This scale distinguishes between the ascending neurological symptoms (ANS), in relation to new signs occurring above the initial post-traumatic metameric level, and the increasing myelopathic symptoms (IMS) in relation to new signs occurring below the initial level. Both ANS and INS have been scored into four grades which are given in Table 1 . The data selected for the study of the MRI were: (1) the vertebral levels of the rostral and caudal extremities of the syrinx; (2) its length; and (3) the presence of severe degenerative phenomena such as myelomalacia and meningeal fibrosis.

\section{Patients}

The patients studied were five men and three women (Table 2), with an age ranging from 17 to 54 years (mean age 30.7 at the time of injury). The paraplegia 
Table 1 Classification of post-traumatic syringomyelia (Silberstein modification classification)

Ascending neurological symptoms (ANS): new neurological signs at or above the initial metameric level

Stage 0

Stage I

Stage II

Stage III

\section{no sign}

light: occasional paraesthesia and dysaesthesia, motor tiredness: loss of one point at the muscle strength scale (MSS), asymetry of reflexes

moderate: frequent pain, hypoaesthesia, motor deficiency (loss of two points at the MSS) starting amyotrophy, unilateral areflexia

severe: intense permanent pain, analgesia, serious paralysis (loss of more than two points at the MSS) and amyotrophy, bilateral areflexia

Increasing myelopathy symptoms (IMS): new neurological signs below the initial metameric level

\begin{tabular}{ll}
\hline Stage 0 & no sign \\
Stage I & $\begin{array}{l}\text { light: loss of one point at the MSS, slow } \\
\text { reflexes, light sensory signs: infrequent }\end{array}$ \\
paraesthesia and hypoaesthesia \\
moderate: loss of two points at the MSS, \\
light spasticity degradation of the vesical \\
sphincter balance (augmentation of post- \\
micturitional leaks and residues), frequent \\
sensory signs \\
stage III \\
MSS, serious spasticity with regidity, urine \\
retention, autonomous hyperreflexia, intense \\
pains and anaesthesia
\end{tabular}

was incomplete in five patients (ASIA/IMSOP grade D and one B). Three had a complete (grade A) or nearly complete (grade B) lesion. Five had a vertebral osteosynthesis performed after the accident, including spinal cord decompression.

The PTS was diagnosed from 2 to 8 years (mean 4.5 years post injury) based on neurological worsening. On MRI, the syrinxes extended between C6 (C1-T3) to $\mathrm{T} 7$ (C4-T12). Their length ranged from 4.5 to $24 \mathrm{~cm}$ (mean $13.5 \mathrm{~cm}$ ). No important degree of myelomalacia nor of meningeal fibrosis was observed. Because of rapid neurological deterioration, the SPS were performed 2-12 months (mean 6 months) after the diagnosis of PTS. In seven patients, the syrinx was approached at its widest part but in patient 5 it had to be at two levels because of septation. The dura was opened and when necessary the meningeal fibrosis was dissected (patients $1,4,6,8$ ). The myelotomy was performed in the midline and corresponded to the thinnest part of the posterior wall of the syrinx and in patient 5 at two levels. A T tube $(1.5 \mathrm{~mm}$ diameter, $40 \mathrm{~mm}$ in length) was placed into the syrinx draining the cerebrospinal fluid (CSF) to the peritoneum ${ }^{6}$ with a pressure-dependent valve. The myelotomy and the dura were closed using fibrinogen glue, so as to make them water-tight. The catheter was securely fixed to the dura to prevent any migration, or CSF leakage. During the operation, a contrast radiological control of the system was systematically performed.

Early postoperative complications occurred in three patients. In patient 1 , severe pain reappeared at the level of the $\mathrm{T} 7$ dermatome, on the right side, after a delay of 1 month. A second surgical procedure was required. The surgeon found an important degree of meningeal fibrosis and a displacement of the catheter near $\mathrm{C} 7$ root on the right. After dissection of adhesions and refixation of the catheter, the pain disappeared completely.

In patient 2, 9 months after the derivation, the IMS and the ANS neurological signs reappeared with the same intensity at the level of T6. The MRI showed persistence of the inferior part of the syrinx from T5 to T7. The peroperative control of the derivation showed dysfunction of the inferior syringo-subarachnoid part of the catheter without any significant degree of meningeal fibrosis. A new syringo-peritoneal catheter was placed in the inferior extremity of the syrinx. The ANS decreased to grade I but the IMS remained at grade II.

Patient 5, 3 months after the SPS, previously complete at $\mathrm{T} 4$, presented a dramatic acute worsening, including tetraplegia with respiratory impairment. The MRI showed a haematomyelia within the syrinx. After an emergency neurosurgical evacuation of the blood clot, the neurological level returned to the initial level.

\section{Results}

The mean term postoperative results, ranging from 3 to 9 years (mean 3.5 years) after the SPS, are summarised in Table 2. An example of MRI concerning patient 7 is shown in Figures 1 and 2. (Note: the appearances had not shown deterioration in scans taken 3 years after the SPS).

The most important findings were as follows.

First, there was a decrease of the neurological level in every patient with a decrease or a stabilisation of the ANS in seven patients. Worsening of the neurological level and the ANS concerned patient 5 and was due to haematomyelia.

Second, there was a decrease or a stabilisation of the IMS and the ASIA/IMSOP grade in four patients cases $(4,6,7,8)$ associated with an increase of these symptoms in the four other patients $(1,2,3,5)$.

Third, there was an important decrease of the syrinxes in five patients $(1,2,3,5,7)$ and a total disappearance in three patients $(4,6,8)$. But, it was associated with an important degree of myelomalacia and/or a meningeal fibrosis in five patients $(1,2$, $3,5,7)$.

Fourth, there was better evolution of the initially complete or nearly complete paraplegia patients $(4,6$, 7) than of those with incomplete paraplegia patients $(1,2,3,5,8)$ with fewer postoperative complications, less in the way of severe neurological symptoms and less in the way of abnormalities as seen on MRI. 
Table 2 General data

\begin{tabular}{|c|c|c|c|c|c|c|c|c|c|c|c|c|c|c|c|c|c|}
\hline \multirow[b]{3}{*}{ Patient } & \multirow[b]{3}{*}{ Sex } & & & & & \multicolumn{6}{|c|}{ Preoperative syringomyelia } & \multicolumn{6}{|c|}{ Late postoperative status } \\
\hline & & \multicolumn{4}{|c|}{ Initial status } & \multicolumn{5}{|c|}{ Neurological status } & \multirow{2}{*}{$\begin{array}{c}\text { MRI } \\
\text { SRCE } \\
(\mathrm{cm})\end{array}$} & \multirow[b]{2}{*}{$\begin{array}{c}D P S P S \\
(y)\end{array}$} & \multicolumn{4}{|c|}{ Neurological status } & \multirow{2}{*}{$\begin{array}{c}M R I \\
\text { SRCE } \\
(\mathrm{cm})\end{array}$} \\
\hline & & Age & $N L$ & $I V T$ & $\begin{array}{c}A S I A / \\
I M S O P \\
S C\end{array}$ & $\begin{array}{c}D P I \\
(y)\end{array}$ & $N L$ & $\begin{array}{c}A S I A / \\
I M S O P \\
s C\end{array}$ & $A N S$ & $I M S$ & & & $N L$ & $\begin{array}{c}A S I A / \\
I M S O P \\
S C\end{array}$ & $A N S$ & $I M S$ & \\
\hline 1 & $\mathbf{M}$ & 33 & $\mathrm{~T} 7$ & No & $\mathrm{D}$ & 2 & $\mathrm{~T} 5$ & $\mathrm{D}$ & I & I & T9 L1 $(7,5)$ & 9 & T5 & $\mathrm{C}$ & I & III & \multirow{4}{*}{$\begin{array}{l}\text { T8 T9 }(3 \mathrm{~cm}) \\
\text { Myel + Arac } \\
\text { T6 T8 }(4,5) \\
\text { Myel } \\
\text { C7 T5 }(9) \\
\text { Myel + Arac } \\
0(0)\end{array}$} \\
\hline 2 & $\mathbf{M}$ & 38 & $\mathrm{~T} 4$ & Yes & $\mathrm{D}$ & 6 & $\mathrm{C} 7$ & $\mathrm{C}$ & II & II & C6 T6 (15) & 6 & $\mathrm{~T} 4$ & $\mathrm{~B}$ & I & III & \\
\hline 3 & $\mathrm{~F}$ & 54 & $\mathrm{~T} 7$ & No & $\mathrm{D}$ & 8 & $\mathrm{~T} 2$ & $\mathrm{C}$ & II & II & $\mathrm{T} 2 \mathrm{~T} 12(16,5)$ & 5 & T5 & $\mathrm{B}$ & I & III & \\
\hline 4 & $\mathbf{M}$ & 23 & $\mathrm{~T} 4$ & Yes & A & 2 & $\mathrm{C} 5$ & A & II & I & C2 T2 (11) & 3 & $\mathrm{~T} 4$ & A & 0 & 0 & \\
\hline 5 & $\mathrm{~F}$ & 17 & $\mathrm{~T} 4$ & Yes & $\mathrm{D}$ & 4 & $\mathrm{~T} 3$ & $\mathrm{C}$ & II & II & C1 T10 (24) & 3 & $\mathrm{~T} 4$ & A & III & III & \multirow{2}{*}{$\begin{array}{l}\text { C4 T5 (12) } \\
\text { Myel } \\
\text { T5 T6 }(3,5)\end{array}$} \\
\hline 6 & $\mathrm{~F}$ & 16 & $\mathrm{~T} 2$ & Yes & A & 4 & $\mathrm{C} 7$ & A & II & II & T2 Т6 $(7,5)$ & 3 & $\mathrm{~T} 2$ & A & 0 & 0 & \\
\hline 7 & $\mathbf{M}$ & 47 & Т9 & Yes & B & 4 & $\mathrm{C} 4$ & B & II & II & C1 T10 (23) & 3 & $\mathrm{C} 7$ & $\mathrm{~B}$ & II & II & $\begin{array}{l}0(0) \\
\text { Myel }\end{array}$ \\
\hline 8 & $\mathbf{M}$ & 18 & $\mathrm{C} 4$ & No & $\mathrm{D}$ & 6 & $\mathrm{C} 3$ & $\mathrm{C}$ & II & II & C4 C6 $(4,5)$ & 4 & $\mathrm{C} 4$ & $\mathrm{D}$ & I & I & $0(0)$ \\
\hline
\end{tabular}

$\mathrm{NL}=$ neurological level; IVT $=$ initial vertebral surgery (decompression and/or stabilisation); DPI $=$ delay post injury (years); ANS = ascending neurological syndrome; IMS = increasing myelopathy syndrome; $\mathrm{SRCE}=$ syrinx rostral caudal extremities; DP SPS = delay post syringo-peritoneal shunting (years); Myel = myelomalacia; Arac $=$ arachnoiditis 


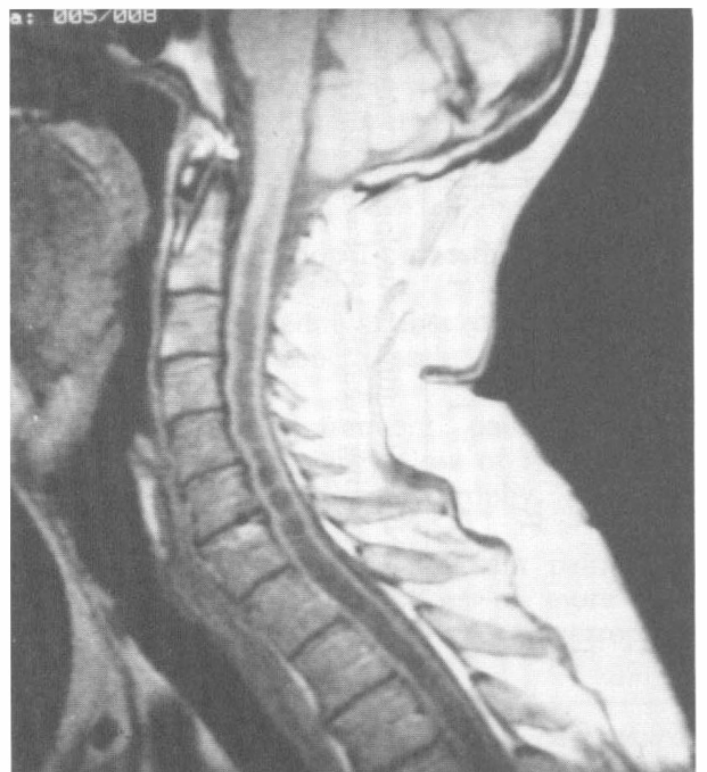

Figure 1 MRI (T1 weighted), before SPS

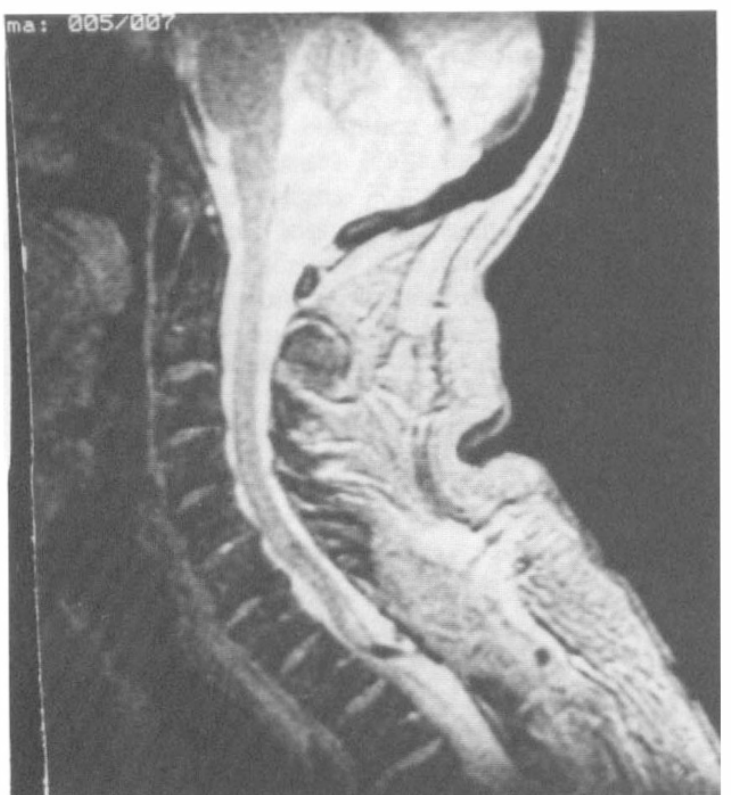

Figure 2 MRI (T2 weighted), 5 months after SPS

\section{Discussion}

SPS is an operation frequently used in the treatment of PTS since reports of the studies of Williams, ${ }^{7}$ Philips $^{8}$ and Pecker. ${ }^{6}$ Short term results seem satisfactory with a decrease of clinical signs in $75-100 \%$ of the patients within 1 year. ${ }^{5,8,9,10-13}$ Some authors mention early mechanical complications ${ }^{14}$ and late worsening. ${ }^{2,15}$ Biyani and El Masry ${ }^{16}$ recently reported a series with a mean follow-up of 3 years. The results are favourable in 13 patients (improvement), fair in six (stabilisation), and poor in three (worsening).

In our study, in three patients $(1,2,5)$ there was an early complication regressing, after surgery, and in four cases $(1,2,3,5)$ a late clinical deterioration, mainly of the IMS. The ANS remained improved or stabilised in seven out of eight patients. The MRI showed a regression of the cavitations in all of the patients (with complete disappearance in three) but associated with a progression of local degenerative phenomena such as myelomalacia and meningeal fibrosis in five patients cases $(1,2,3,5,7)$.

We could put forward the hypothesis of a correlation between the volume of the cavity and the ANS, and another correlation between the degenerative phenomena around the cavity and the IMS. Rossier ${ }^{15}$ in an anatomopathological study of a patient, who had shown very little benefit after a SPS, found nearly complete collapse of the syrinx associated with extensive pericavital gliosis. The SPS appears to control the volume of the cavity but not the local degenerative phenomena. Besides, it is most likely that opening the dura and the presence of the catheter favour the development of chronic inflammatory mechanisms. ${ }^{17}$

We require to emphasise the poor outcome of patients with incomplete paraplegia. The deterioration of the clinical status (correlated by RMI findings) occurred in five patients. On the other hand, the three patients with a complete or nearly complete lesion have all improved or become clinically stabilised. This phenomenon could in part be explained by greater physical activity in those with incomplete than in those with complete lesions. This could possibly lead to an increase of the epidural venous pressure, the so called 'slosh' phenomenon. ${ }^{2,3,16,18}$ Another hypothesis could be related to an untimely displacement of the material in association with the increased mobility of these patients.

\section{Conclusion}

Syringo-peritoneal shunting remains a useful surgical technique for patients with an evolving PTS, especially in ANS. Nevertheless, it is insufficient in the long term to control the degenerative phenomena occurring around the cavity as well as the IMS, especially in patients with incomplete paraplegia.

\section{References}

1 Umbach I, Heilporn A. Post spinal cord injury syringomyelia. Paraplegia 1991; 29: 219-221.

2 Williams B. Post traumatic syringomyelia (cystic myelopathy). In: HL Frankel (ed). Handbook of Clinical Neurology (Revised Series) Vol 17 (61). Elsevier Science Publishers BV: Amsterdam, 1992; pp 375-398.

3 Williams B. Post traumatic syringomyelia. An up-date. Paraplegia 1990; 28: 296-313.

4 Dituno JF, Young W, Donovan WH, Creasey G. The international standards booklet for neurological and functional classification of spinal cord injury. Paraplegia 1994; 32: 70-80.

5 Silberstein M, Hennessy O. Cystic cord lesions and neurological deterioration in spinal cord injury: operative considerations based on magnetic resonance imaging. Paraplegia 1992; 30: 661-668.

6 Pecker J, Javalet A, Boutelis A. La dérivation syringo-péritonéale. Neurochirurgie 1983; 29: 171-173. 
7 Williams B. Communicating syringomyelia presenting immediately after trauma. Acta Neurochir 1971; 24: 97-106.

8 Philips TW, Kindt GW. Syringo-peritoneal shunt for syringomyelia: a preliminary report. Surg Neurol 1981; 16: 462-466.

9 Peerless SJ, Durward QJ. Management of syringomyelia: a pathophysiological approach. Clin Neurosurg 1983; 30: 531-576.

10 Vernon ID, Silver JR, Symon L. Post traumatic syringomyelia: the results of surgery. Paraplegia 1983; 21: 37-46.

11 Barbaro NM, Wilson CB, Gutin Ph. Surgical treatment of syringomyelia: favourable results with syringo-peritoneal shunting. J Neurosurg 1984; 61: 531-538.

12 Shannon $\mathbf{N}$ et al. Clinical features, investigation and treatment of post-traumatic syringomyelia. J Neurol Neurosurg Psychiatry 1981; 44: 35-42.

13 Suzuki M, Davis C, Symon L, Gentili F. Syringo-peritoneal shunt for treatment of cord cavitation. J Neurol Neurosurg Psychiatry 1985; 48: 620-627.

14 Wester K, Pederson PH, Krakenes J. Spinal cord damage caused by rotation of a $\mathrm{T}$ drain in a patient with a syringoperitoneal shunt. Surg Neurol 1989; 31: 224-227.

15 Barnett HJM, Jousse AT. Post traumatic syringomyelia (cystic myelopathy). In: PJ Vinken and GW Bruyn (eds). Handbook of Clinical Neurology, Vol 26. North Holland: Amsterdam, New York, pp 113-157.

16 Biyani A, El Masry WS. Post traumatic syringomyelia: a review of the literature. Paraplegia 1994; 32: 723-731.

17 Rossier AB, Bignami A, Foo D. A case of post traumatic syringomyelia. Neuropathological findings after one year of cystic drainage. Paraplegia 1986; 24: 63-69.

18 Rossier AB, Foo D, Shillito J, Dyro JM. Post traumatic cervical syringomyelia. Brain 1985; 108: 439-461. 